\title{
Susceptibility of Cucurbit Rootstocks to Didymella bryoniae and Control of Gummy Stem Blight on Grafted Watermelon Seedlings with Fungicides
}

\author{
Anthony P. Keinath, Clemson University, Coastal Research and Education Center, Charleston, SC 29414-5329
}

\begin{abstract}
Keinath, A. P. 2013. Susceptibility of cucurbit rootstocks to Didymella bryoniae and control of gummy stem blight on grafted watermelon seedlings with fungicides. Plant Dis. 97:1018-1024.

Seedlings of watermelon are susceptible to Didymella bryoniae, the cucurbit pathogen that causes gummy stem blight, particularly when they are grown in the greenhouse for use as transplants. Seedlings of bottle gourd (Lagenaria siceraria) and interspecific hybrid squash (Cucurbita moschata $\times$ C. maxima) that are used as rootstocks for grafting watermelon are susceptible to gummy stem blight when wounded. Nonwounded rootstock seedlings of both genera were as susceptible to gummy stem blight as seedless watermelon. Because grafted plants must be misted or held at high relative humidity for 1 week so the graft union will heal, fungicides may be necessary to manage gummy stem blight under these disease-conducive environmental conditions. Nine fungicides were applied as foliar treatments at labeled rates per 467 liters/ha water to nongrafted seedlings of watermelon and five rootstock cultivars. Fluopyram + tebuconazole injured all five bottle gourd and hybrid squash cultivars and stunted watermelon and

hybrid squash seedlings. Cyprodinil + difenoconazole injured all five rootstock cultivars and watermelon. Tebuconazole stunted bottle gourd and watermelon seedlings. Four of the five fungicides that were not phytotoxic reduced incidence and severity of gummy stem blight on seedless watermelon grafted onto bottle gourd Emphasis and hybrid squash Strong Tosa. Difenoconazole and cyprodinil were more effective than mancozeb or cyprodinil + fludioxonil, which were more effective than thiophanate-methyl, which was not significantly different from the water control $(P=0.01)$. Nongrafted watermelon seedlings and watermelon seedlings grafted onto watermelon as the rootstock were as susceptible to gummy stem blight as watermelon seedlings grafted onto cucurbits. Although difenoconazole and cyprodinil are not registered currently on cucurbits, transplant growers can apply mancozeb or cyprodinil + fludioxonil to manage gummy stem blight on watermelon and rootstock seedlings during greenhouse production.
\end{abstract}

Grafting of watermelon (Citrullus lanatus (Thunb.) Matsum. \& Nakai var. lanatus) is used in various countries, notably Korea, Japan, and Israel, to manage soilborne pathogens, confer cold tolerance, or increase yield $(9,26)$. The two most common rootstocks used for grafting watermelon are bottle gourd, Lagenaria siceraria (Molina) Standl., and an interspecific hybrid of two squash species, Cucurbita moschata Duch. ex. Poir $\times$ C. maxima Duch. ex. Lam $(23,29)$. Several cultivars of each rootstock species are available from international seed companies.

The occurrence of gummy stem blight on watermelon seedlings is a well-known problem in greenhouses where transplants are produced $(7,16-18,24,36)$. Gummy stem blight is caused by the ascomycete Didymella bryoniae (Auersw.) Rehm (anamorph Stagonosporopsis cucurbitacearum (Fr.) Aveskamp, Gruyter \& Verkley [2], synonym Phoma cucurbitacearum (Fr.:Fr.) Sacc.). The pathogen is seedborne on a variety of cucurbits, including watermelon and $C$. pepo $(6,16,28)$.

In addition to watermelon, D. bryoniae infects cucurbit species used as rootstocks, including $C$. moschata, C. maxima, and $L$. siceraria. In fields in Trinidad, $D$. bryoniae caused damping-off of pumpkin (probably C. moschata) seedlings (3). In various tests under controlled conditions, $D$. bryoniae isolates were pathogenic on wounded seedlings of C. maxima and C. maxima subsp. andreana $(8,15)$. The pathogen also infected wounded vines of mature $C$. maxima $(8,13)$. D. bryoniae has been reported to occur naturally on L. siceraria in Southeast Asia $(32,37)$. The pathogen also infected wounded seedlings and wounded vines of mature $L$. siceraria (reported as L. vulgaris and L. leucantha, which now are synonyms of L. siceraria) in pathogenicity tests $(8,13)$. In another study, the

Corresponding author: A. P. Keinath, E-mail: tknth@clemson.edu

Accepted for publication 7 February 2013.

http://dx.doi.org/10.1094/PDIS-12-12-1133-RE

(C) 2013 The American Phytopathological Society rootstock cultivar $C$. moschata $\times C$. maxima 'Teksukabutu' was infected after stem wounding and inoculation, although it was less susceptible than watermelon (11).

The use of grafted cucurbits may increase the risk of gummy stem blight development in the greenhouse (18). Both the rootstock and the scion are wounded when the top of the rootstock and the bottom of the scion are removed, regardless of which grafting method is used (14). Because D. bryoniae infects wounded cucurbit species used as rootstocks, rootstock seedlings could become infected during grafting or immediately after grafting before healing. After grafting, plants are held at high humidity or under frequent misting for 1 week to promote healing of the graft union (14). These very moist environmental conditions are favorable for rapid development of gummy stem blight (1).

The circumstances around one documented outbreak of gummy stem blight on grafted watermelon in the field suggest that infection occurred during grafting (4). Cankers of gummy stem blight that developed at the graft union became so severe that affected plants died. Gummy stem blight was not observed on nongrafted plants in the same field in Tunisia or on leaves of grafted plants. Since it is very unlikely that another source of $D$. bryoniae inoculum was present in the arid North African climate, it appears that the grafted plants became infected during grafting. Koch's postulates were fulfilled with $D$. bryoniae inoculated onto wounded seedlings of the rootstock cultivar $C$. moschata $\times$ C. maxima 'Strong Tosa' (4).

Because results from most inoculation studies were obtained with wounded seedlings, it is not known how susceptible to gummy stem blight nonwounded rootstock Cucurbita and Lagenaria seedlings are. This information is necessary to determine how likely gummy stem blight is to occur on cucurbit rootstock seedlings during production before grafting. The relative susceptibility of Lagenaria rootstock cultivars compared to watermelon also is unknown, and only two cultivars of $C$. moschata $\times C$. maxima used to graft watermelon have been tested for susceptibility to gummy stem blight.

Until recently, mancozeb was the only fungicide effective against $D$. bryoniae that could be applied to cucurbits in green- 
houses. Chlorothalonil (in flowable formulations), strobilurins, and boscalid may not be applied in greenhouses. Although thiophanatemethyl could be used in greenhouses, many $D$. bryoniae isolates are insensitive to this active ingredient (22). Applications of several newly registered fungicides, including cyprodinil, cyprodinil + difenoconazole, cyprodinil + fludioxonil, difenoconazole, tebuconazole, and tebuconazole + fluopyram, are not prohibited in greenhouses. However, some of these fungicides may potentially be phytotoxic to cucurbits other than those used to establish fungicide tolerances, which are cucumber (Cucumis sativus L.), melon (C. melo L.), and summer squash (Curcurbita pepo L.) (30). Phytotoxicity or stunting were observed when tebuconazole and cyprodinil + fludioxonil were applied three times to seedlings of $L$. siceraria 'Emphasis' and hybrid Curcurbita 'Strong Tosa' at 935 liters/ha rates (20).

The objectives of this study were to determine (i) the relative susceptibility of nonwounded seedlings of Lagenaria and Cucurbita used as rootstocks for watermelon and (ii) the crop safety and efficacy of fungicides that control gummy stem blight in the field on grafted watermelon seedlings in the greenhouse.

\section{Materials and Methods}

Host plants. The seedless watermelon cultivar used was 'SuperSeedless ${ }^{\circledR}$ 7187HQ' (Nunhems USA, Inc., Parma, ID). Three Lagenaria rootstocks, 'Emphasis' (Syngenta Seeds, Inc., Boise, ID), 'Macis' (Nunhems), and 'WMXP 3945' (Harris Moran Seed Co., Modesto, CA), and two hybrid Cucurbita rootstocks, 'Strong Tosa' (Syngenta) and 'Shintosa Camel' (Nunhems), were used. Because the three genera have different growth rates, seeding was staggered over time. This is the standard practice to ensure all plants are at the correct growth stage for grafting. The rootstock is ready to graft when the first true leaf starts to develop; the scion should have the first true leaf fully open. Watermelon was seeded first, Lagenaria was seeded when watermelon seedlings had fully expanded cotyledons, and Cucurbita was seeded 2 days after Lagenaria. When nongrafted seedlings were used in experiments, they were transplanted from 72 -cell flats into 10 -cm-diameter pots 1 day before use.

Evaluation of rootstock susceptibility to $D$. bryoniae. Nongrafted seedlings of the five rootstock cultivars and seedless watermelon were tested for susceptibility to D. bryoniae. Two strobilurin- and boscalid-insensitive isolates of $D$. bryoniae originally isolated from watermelon in South Carolina, HD10 and W764, were used $(17,19)$. The experimental design was a split plot, with isolate as the whole plot and cultivar as the subplot. There were four replicate pots (experimental units) with three seedlings per pot per treatment. Isolates were tested separately over time, and each isolate was tested twice.

Inoculum of $D$. bryoniae was prepared from cultures grown on one-quarter strength potato dextrose agar incubated with a 16-h photoperiod as described previously $(17,19)$. The inoculum concentration was 2 or $3 \times 10^{5}$ ascospores and conidia per milliliter sterile $0.1 \%$ sucrose- $0.05 \%$ hydrolyzed casein solution. This inoculum level was lower than the level used in the previous studies, because inoculated plants were incubated twice as long, as described below. (In preliminary tests, an inoculum level of $1 \times 10^{3}$ spores $/ \mathrm{ml}$ was insufficient to cause any disease, and development of gummy stem blight was variable with $1 \times 10^{4}$ spores $/ \mathrm{ml}$; data not shown). Noninoculated seedlings were sprayed with sterile sucrose-casein solution. Immediately after inoculation, seedlings were placed into $1 \times 2 \times 1 \mathrm{~m}$ chambers in which cool-mist atomizing humidifiers (Trion Herrmidifier, Sanford, NC), one per chamber, were used to maintain $100 \%$ relative humidity. Each replication was placed in a separate humidity chamber for 6 days. Disease incidence was determined as the percentage of infected seedlings out of three in each pot. Disease severity was rated as the percentage of symptomatic area on each seedling on a 0 to $100 \%$ scale with $5 \%$ increments plus $1 \%$ for plants with one small leaf spot. Severities were averaged across the three seedlings (subsamples) per pot. If only one seedling in a pot was rated as having $1 \%$ severity, the leaf spot was cultured as described previously to verify infection by $D$. bryoniae (19).

Evaluation of fungicides for phytotoxicity. The treatment list of fungicides used included those registered for use on cucurbits against gummy stem blight that were not prohibited from being used in the greenhouse. The highest fungicide rate labeled to manage gummy stem blight was dissolved in the equivalent of 467 liters/ha water (Table 1). The experimental design was a randomized complete block with three replicate pots per treatment in the first two experiments and four replicate pots in the third experiment. One rootstock seedling and three watermelon seedlings were used per pot. Fungicides were applied with a handheld pump-pressurized sprayer. Treated seedlings were held in a greenhouse, and severity of phytotoxicity was rated 7 days after each application. In the first phytotoxicity experiment, seedlings of the five rootstocks were treated with fungicides or water twice at weekly intervals (Table 2). Because the true leaves are removed during grafting, they were removed before the second application. In the second phytotoxicity experiment, watermelon seedlings with two fully expanded true leaves were treated once with fungicides or water (Table 3). In the third phytotoxicity experiment, Lagenaria rootstocks and watermelon were treated with fungicides or water twice at weekly intervals (Tables 2 and 3). The separate experiments with rootstocks and watermelon were done twice, and the combined experiment was done once; repetitions of experiments will be referred to as trials.

Evaluation of fungicide efficacy. The five fungicides that were not phytotoxic on rootstock or watermelon seedlings were evaluated for efficacy against gummy stem blight on seedless watermelon grafted onto L. siceraria 'Emphasis' or hybrid Cucurbita 'Strong Tosa.' These cultivars were chosen as representative cultivars of the two rootstock species. Each rootstock was tested twice in separate trials. Fungicides, used at the same rates that were evaluated for phytotoxicity, were applied to rootstock and scion seed-

Table 1. Fungicides used in this study

\begin{tabular}{|c|c|c|c|c|c|}
\hline Common name & $\begin{array}{l}\text { Trade name } \\
\text { and formulation }\end{array}$ & Manufacturer & $\begin{array}{l}\text { Labeled rate } \\
\left(\mathrm{kg} \mathrm{a.i./ha)^{x }}\right.\end{array}$ & $\begin{array}{l}\text { Amount of product } \\
\text { used (per } 0.5 \text { liter) }\end{array}$ & $\begin{array}{c}\text { Labeled on } \\
\text { cucurbits in } 2013\end{array}$ \\
\hline Copper hydroxide & Kocide 3000 DF & E. I. du Pont de Nemours & 0.42 & $1.50 \mathrm{~g}$ & Yes \\
\hline Cyprodinil & Vangard $75 \mathrm{WG}$ & Syngenta Crop Protection & 0.37 & $0.53 \mathrm{~g}$ & No \\
\hline Cyprodinil + difenoconazole & Inspire Super 2.82EW & Syngenta Crop Protection & $0.37+0.13$ & $1.56 \mathrm{ml}$ and $0.78 \mathrm{ml}^{\mathrm{y}}$ & Yes \\
\hline Cyprodinil + fludioxonil & Switch 62.5WG & Syngenta Crop Protection & $0.37+0.25$ & $1.05 \mathrm{~g}$ & Yes \\
\hline Difenoconazole & Inspire $2.08 \mathrm{SC}$ & Syngenta Crop Protection & 0.13 & $0.55 \mathrm{ml}$ & No \\
\hline Fluopyram + tebuconazole & Luna Experience 400SC & Bayer CropScience & $0.25+0.25$ & $1.33 \mathrm{ml}$ and $0.66 \mathrm{ml}^{\mathrm{y}}$ & $\mathrm{Yes}^{\mathrm{Z}}$ \\
\hline Mancozeb & Manzate Prostick 75DG & United Phosphorus (UPI) & 2.52 & $3.60 \mathrm{~g}$ & Yes \\
\hline Tebuconazole & Monsoon 3.6F & Loveland Products & 0.25 & $0.62 \mathrm{ml}$ & Yes \\
\hline Thiophanate-methyl & Topsin M WSB 70WP & Cerexagri-Nisso & 0.28 & $0.60 \mathrm{~g}$ & Yes \\
\hline
\end{tabular}

\footnotetext{
${ }^{\mathrm{x}}$ Maximum labeled rate for applications to manage gummy stem blight.
}

${ }^{y}$ Cyprodinil + difenoconazole and fluopyram + tebuconazole were tested at full and half rates in the second repetition of the first phytotoxicity experiment and in the second and third phytotoxicity experiments.

${ }^{z}$ Currently labeled only on watermelon among cucurbit crops. 
lings 1 day before grafting. Greenhouse flats with 72 cells were cut into 6-cell sections (one experimental unit), and the seedlings were treated with the appropriate fungicide. When the seedlings were grafted, rootstock and scion that had been treated with the same fungicide were matched. On the rootstock seedling, one cotyledon and the visible growing point were cut away with a razor blade at a 45-degree angle. The hypocotyl of the scion below the cotyledons was cut at a 45-degree angle on one side only. The cut sides were matched and held together with a grafting clip (14). Grafting controls included nongrafted seedless watermelon and self-grafted watermelon, i.e., watermelon used as the rootstock and scion. A nongrafted, inoculated watermelon treatment was tested in both trials with rootstock Emphasis and in the second trial with rootstock Strong Tosa. Grafted plants and the nongrafted control were moved to a healing chamber with $100 \%$ relative humidity for $24 \mathrm{~h}$.

After $24 \mathrm{~h}$, the plants were inoculated with $D$. bryoniae isolate HD10 by spraying with a suspension of $2 \times 10^{5}$ spores $/ \mathrm{ml}$. Plants were returned to the healing chamber immediately after inoculation and held at 100\% relative humidity for an additional 6 days. Disease incidence and severity were rated as described above on the rootstock portion and the scion portion of each grafted plant.

Table 2. Phytotoxicity of fungicides on seedlings of three Lagenaria rootstocks and two Cucurbita rootstocks in the greenhouse ${ }^{\mathrm{u}}$

\begin{tabular}{|c|c|c|c|c|c|c|c|}
\hline \multirow[b]{2}{*}{ Fungicide (rate) } & \multicolumn{4}{|c|}{$\begin{array}{c}\text { Occurrence and severity of injury (\%) } \\
\text { on Lagenaria } \text { cultivars }^{v}\end{array}$} & \multicolumn{3}{|c|}{$\begin{array}{c}\text { Occurrence and severity of injury (\%) } \\
\text { on Cucurbita cultivars }\end{array}$} \\
\hline & $\mathbf{P} / \mathbf{N}^{\mathbf{w}}$ & Emphasis & Macis & WMXP 3945 & $\mathbf{P} / \mathbf{N}$ & Shintosa Camel & Strong Tosa \\
\hline Water & $0 / 3$ & $0.0 \mathrm{~b}^{\mathrm{x}}$ & $0.0 \mathrm{c}$ & $0.0 \mathrm{~b}$ & $0 / 2$ & $0.0 \mathrm{c}$ & $0.0 \mathrm{c}$ \\
\hline Cyprodinil + difenoconazole (full) & $2 / 3$ & $17.0 \mathrm{a}$ & $26.6 \mathrm{a}$ & $13.1 \mathrm{a}$ & $1 / 2$ & $16.9 \mathrm{a}$ & $11.8 \mathrm{a}$ \\
\hline Fluopyram + tebuconazole (full) & $3 / 3$ & $14.4 \mathrm{a}$ & $22.3 \mathrm{a}$ & $20.7 \mathrm{a}$ & $1 / 2 *$ & $7.4 \mathrm{ab}$ & $5.7 \mathrm{ab}$ \\
\hline Copper hydroxide & $2 / 3$ & $9.4 \mathrm{a}$ & $5.0 \mathrm{~b}$ & $10.6 \mathrm{a}$ & $1 / 2$ & $4.0 \mathrm{~b}$ & $5.7 \mathrm{ab}$ \\
\hline Tebuconazole & $2 / 3 *$ & $1.4 \mathrm{~b}$ & $3.6 \mathrm{bc}$ & $0.4 \mathrm{~b}$ & $2 / 2 *$ & $1.0 \mathrm{bc}$ & $1.0 \mathrm{bc}$ \\
\hline Cyprodinil + fludioxonil & $2 / 3$ & $2.9 \mathrm{ab}$ & $0.1 \mathrm{c}$ & $0.1 \mathrm{~b}$ & $0 / 2$ & 0.0 & 0.0 \\
\hline Mancozeb & $1 / 3$ & $0.8 \mathrm{~b}$ & $0.0 \mathrm{c}$ & $0.1 \mathrm{~b}$ & $0 / 2$ & 0.0 & 0.0 \\
\hline Fluopyram + tebuconazole (half) ${ }^{\mathrm{y}}$ & $2 / 2$ & 6.0 & 4.0 & 15.3 & $1 / 1 *$ & 0.0 & 0.0 \\
\hline Cyprodinil + difenoconazole (half) & $1 / 2$ & 7.0 & 11.7 & 17.0 & $0 / 1$ & 0.0 & 0.0 \\
\hline Thiophanate-methyl ${ }^{z}$ & $0 / 3$ & 0.05 & 0.0 & 0.05 & $0 / 2$ & 0.0 & 0.0 \\
\hline Difenoconazole ${ }^{\mathrm{z}}$ & $0 / 3$ & 0.0 & 0.0 & 0.0 & $0 / 2$ & 0.0 & 0.0 \\
\hline Cyprodinil $^{\mathrm{z}}$ & $0 / 3$ & 0.0 & 0.0 & 0.0 & $0 / 2$ & 0.0 & 0.0 \\
\hline$P$ value for comparisons & & 0.01 & 0.003 & 0.0025 & & 0.0075 & 0.002 \\
\hline
\end{tabular}

u Values are means of three replications in both repetitions of the first rootstock phytotoxicity experiment except for half rates of fluopyram + tebuconazole and cyprodinil + difenoconazole, which were only included in the second repetition.

v Injury was rated with a 16-point Horsfall-Barratt-type scale as percent necrotic leaf area. Values are back-transformed least-squares means from the arcsine of the square root.

${ }^{\mathrm{w}} \mathrm{P}$ is the number of trials in which phytotoxicity as injury or stunting was observed, and $\mathrm{N}$ is the number of trials done. Treatments that stunted seedlings are marked with an asterisk

${ }^{\mathrm{x}}$ Means followed by the same letter within columns are not significantly different at the probability given in the last row of the column based on $t$ tests of least-squares means. Means within a column without letters are from treatments not included in the analysis of variance to eliminate inequality of variance among treatments.

${ }^{y}$ Half rates (see Table 1) were tested in the second repetition of the first rootstock phytotoxicity experiment. Means for the half rates applied to Lagenaria cultivars were significantly different from the water control in a separate analysis of the second repetition of the first rootstock phytotoxicity experiment.

$\mathrm{z}$ Treatments not included in any analysis of variance to eliminate inequality of variance among treatments.

Table 3. Phytotoxicity of fungicides on seedlings of seedless watermelon 'SuperSeedless® 7187HQ' in the greenhouse

\begin{tabular}{|c|c|c|c|c|}
\hline \multirow[b]{2}{*}{ Fungicide (rate) } & \multicolumn{2}{|c|}{ Stunting $(\%)^{\mathrm{v}}$} & \multicolumn{2}{|c|}{ Injury } \\
\hline & Trial 1 & Trial 2 & Number of trials ${ }^{w}$ & Severity $(\%)^{x}$ \\
\hline Water & $0.0 \mathrm{c}^{\mathrm{y}}$ & $0.0 \mathrm{c}$ & 0 & $0.0 \mathrm{~b}$ \\
\hline Tebuconazole & $65.4 \mathrm{a}$ & $54.0 \mathrm{a}$ & 1 & $1.8 * \mathrm{z}$ \\
\hline Fluopyram + tebuconazole (full) & $46.7 \mathrm{a}$ & $15.4 \mathrm{~b}$ & 1 & $4.4^{*}$ \\
\hline Fluopyram + tebuconazole (half) & $8.8 \mathrm{~b}$ & $0.0 \mathrm{c}$ & 0 & 0.2 \\
\hline Cyprodinil + difenoconazole (full) & 0.0 & 0.0 & 3 & $7.3 \mathrm{a}$ \\
\hline Copper hydroxide & 0.0 & 0.0 & 1 & $0.8 *$ \\
\hline Cyprodinil & 0.0 & 0.0 & 1 & $0.6^{*}$ \\
\hline Mancozeb & 0.0 & 0.0 & 0 & 0.2 \\
\hline Thiophanate-methyl & 0.0 & 0.0 & 0 & 0.2 \\
\hline Cyprodinil + fludioxonil & 0.0 & 0.0 & 0 & 0.0 \\
\hline Cyprodinil + difenoconazole (half) & 0.0 & 0.0 & 0 & 0.0 \\
\hline Difenoconazole & 0.0 & 0.0 & 0 & 0.0 \\
\hline$P$ value for comparisons & 0.01 & 0.0001 & & 0.0001 \\
\hline
\end{tabular}

${ }^{v}$ Reduction in height, relative to the water control. Means were calculated from three replications in the first repetition of the first watermelon phytotoxicity experiment and four replications in the second experiment, which was done once. Fungicides were applied once in the first watermelon phytotoxicity experiment and twice in the second experiment. Values are back-transformed least-squares means from the arcsine of the square root.

${ }^{w}$ Number of trials out of three in which injury was observed. A mean severity $\leq 0.33 \%$ was considered to be insignificant.

x Injury was rated with a 16-point Horsfall-Barratt-type scale as percent necrotic leaf area. Means were calculated from three replications in the first repetition of the first watermelon phytotoxicity experiment, except the mean for cyprodinil + difenoconazole, which was calculated from three replications in both repetitions of the first experiment and four replications in the second experiment, which was done once. Values are back-transformed least-squares means from the arcsine of the square root. Means within a column without letters are from treatments not included in the analysis of variance to eliminate inequality of variance among treatments.

${ }^{y}$ Means followed by the same letter within columns are not significantly different at the probability given in the last row of the column based on $t$ tests of least-squares means. Means within a column without letters are from treatments not included in the analysis of variance to eliminate inequality of variance among treatments.

${ }^{\mathrm{z}}$ Means with an asterisk were not significantly different from the water control in an analysis of variance of repetition one of the first experiment. 
Disease severity ratings on rootstock and scion were converted to percentages and averaged across the six seedlings.

Because disease severity ratings were based on the surface area of grafted seedlings, the relative surface areas of scion and rootstock were calculated. Grafted plants produced with the one-cotyledon grafting procedure included the first true leaf plus both cotyledons of the watermelon scion and one cotyledon of the rootstocks (14). Leaves and cotyledons of watermelon and cotyledons of rootstocks Emphasis and Strong Tosa were removed from six plants and laid on a flat-bed scanner. The images were scanned, and surface area based on pixels was determined with Assess 2.0 (APS Press, St. Paul, MN). The mean scion leaf and cotyledon area was $53.5 \%$ of the total area of a grafted plant, and the mean rootstock cotyledon area for both rootstock cultivars was $46.5 \%$ of the total area. The mean severities for rootstock and scion were used to calculate a mean plant severity, weighted by area of rootstock and scion, for each experimental unit.

Data analysis. Data were analyzed with SAS PROC MIXED (SAS Version 9.2, SAS Inc., Cary, NC). When subsets of the data were analyzed and trial was not included in the model, equality of variance between the trials included in the analysis was checked using Bartlett's test (35). Residuals from models were checked for normality using the Shapiro-Wilk statistic, and residuals from models were plotted against predicted $y$ values to check equality of variance. To eliminate problems with non-normality and inequality of variance in some data sets, percentage ratings were transformed with arcsine-square root before analysis. When the arcsine-square root transformation did not eliminate inequality of variance, Taylor's power law was used with $b=1.6$, which means the 0.2-root of data values was used $(21,31)$. Means of transformed data were back-transformed for presentation. Because the phytotoxicity data included many ratings that were 0 , treatments with a mean rating $\leq 0.33 \%$ were excluded from some analyses to eliminate inequality of variance among treatments. Phytotoxicity data for the two Cucurbita cultivars were analyzed together, and the three Lagenaria cultivars and watermelon were all analyzed separately. In analyses, trials, fungicides, and rootstock cultivars or grafting treatments and their interactions were tested as fixed effects, whereas replication was tested as a random effect. The slice option in PROC MIXED was used to examine treatment levels within significant interactions.

\section{Results}

Susceptibility of rootstocks to $D$. bryoniae. Gummy stem blight developed on all five rootstocks and on watermelon after inoculation in all trials. Mean incidence (percentage of plants diseased) across cultivars was 93 and $100 \%$ in trials 1 and 2, respectively, when isolate W764 was used, and 72 and $93 \%$ when isolate HD10 was used. (Incidence was not analyzed due to inequality of variance that could not be eliminated by transforming the data.) All noninoculated seedlings were symptomless, except one noninoculated Macis seedling in trial 2 was infected by HD10 and had a severity of $1 \%$. Cultivars did not differ based on severity of gummy stem blight $(P=0.48)$, and there was no isolate-by-cultivar interaction $(P=0.11)$. Inoculation with isolate W764 resulted in a higher mean severity $(P=0.02)$ across trials and cultivars, $10.8 \%$, than inoculation with HD10, with a mean severity of $5.1 \%$. Mean severity was higher in trial 2 than in trial $1(P=0.02)$. This difference was due primarily to two cultivars, watermelon and WMXP 3945, that had more severe gummy stem blight in trial 2 than in trial $1(P$ $\leq 0.003$ ) (Fig. 1).

Phytotoxicity of fungicides. Phytotoxicity symptoms were rated as injury with necrotic spots on cotyledons or leaves of seedlings and as stunting of seedlings with shortened hypocotyls. Occurrence of phytotoxicity was consistent across replications within a trial but was variable for some fungicides across trials. In the first phytotoxicity experiment with rootstocks, no phytotoxicity was visible after one fungicide application. In the third phytotoxicity experiment, one seedling of WMXP 3945 had necrotic symptoms after one application of tebuconazole. After two fungicide applica- tions, necrosis was present on some Lagenaria seedlings in all three trials and on Cucurbita seedlings only in the first of two trials. Three fungicides, fluopyram + tebuconazole, cyprodinil + difenoconazole, and copper hydroxide, injured seedlings of all five rootstock cultivars (Table 2 ). In general, the high rates of cyprodinil + difenoconazole and fluopyram + tebuconazole caused the greatest injury on Lagenaria, and cyprodinil + difenoconazole caused the greatest injury on Cucurbita. In the second trial of the first phytotoxicity experiment, half rates of cyprodinil + difenoconazole and fluopyram + tebuconazole also caused necrosis on Lagenaria cultivars, 8.2 and $7.4 \%$, respectively. Although severity of necrosis was significantly $(P<0.01)$ lower than with the full rates, it still was significantly greater than in the water control $(P \leq$ $0.0002)$. In the first experiment, copper hydroxide also caused a moderate degree of injury on all five rootstock cultivars, and the severity of necrosis was significantly greater than in the water control $(P<0.01)$. The degree of injury caused by the remaining three fungicides included in the analyses, tebuconazole, cyprodinil + fludioxonil, and mancozeb, was not significantly greater than the ratings for the water control, which had no symptoms resembling injury in either trial (Table 2). Thiophanate-methyl, difenoconazole, and cyprodinil caused no phytotoxicity in either experiment.

Fewer fungicides caused injury on watermelon than on rootstock species. On watermelon, only cyprodinil + difenoconazole caused statistically significant injury compared to the water control (Table 3 ). Mean necrosis ratings of $1.9,13.3$, and $6.8 \%$ severity were observed in phytotoxicity experiment 2 in trials 1 and 2 and in phytotoxicity experiment 3 , respectively, on watermelon seedlings treated with cyprodinil + difenoconazole. Injury was present after one application in phytotoxicity experiment 2 but only after two applications in experiment 3 . The fungicides fluopyram + tebuconazole (high rate), tebuconazole, copper hydroxide, and cyprodinil caused slight injury in phytotoxicity experiment 2 trial 1, but the severity of necrosis with these four fungicides was not significantly different from the water control (Table 3). The low rates of cyprodinil + difenoconazole and fluopyram + tebuconazole and mancozeb, thiophanate-methyl, cyprodinil + fludioxonil, and difenoconazole caused no or essentially no injury on watermelon.

Stunting was more severe on watermelon than on rootstock cultivars. In the first rootstock phytotoxicity experiment, tebuconazole stunted seedlings of all five rootstock cultivars in the first trial and Cucurbita seedlings in the second trial. In addition, both rates of fluopyram + tebuconazole also stunted Cucurbita seedlings slightly in the second trial. On watermelon, the high rate of fluopy-

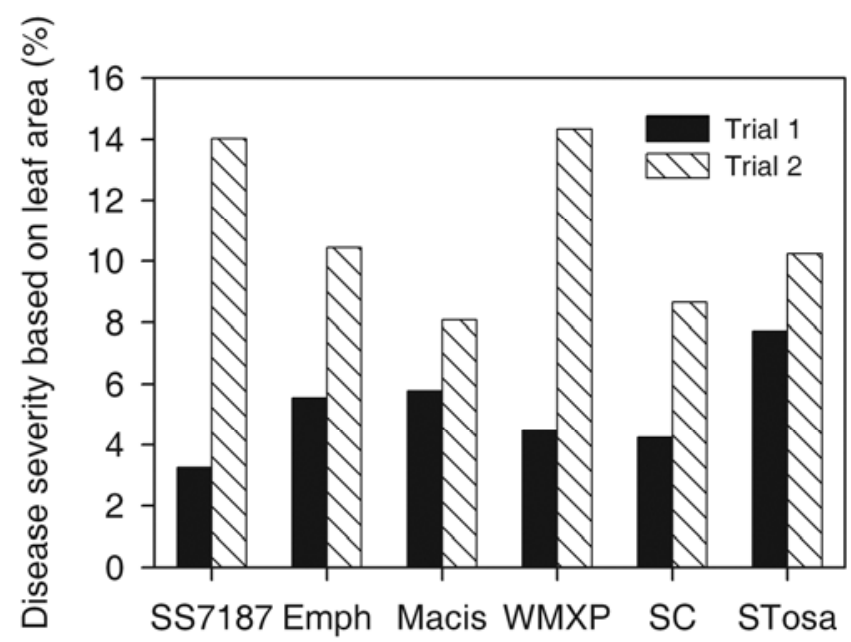

Fig. 1. Severity of gummy stem blight on seedless watermelon 'SS7187' and five rootstock cultivars inoculated in the greenhouse. Rootstock cultivars were Lagenaria siceraria 'Emphasis' (Emph), 'Macis', and 'WMXP 3945' and hybrid Cucurbita 'Shintosa Camel' (SC) and 'Strong Tosa' (STosa). Values for watermelon and WMXP 3945 differed in trial 1 and trial $2(P \leq 0.003)$. Severity did not differ among cultivars. 
ram + tebuconazole and tebuconazole caused stunting in two of the three phytotoxicity trials, the first trial of the second phytotoxicity experiment and the third experiment, while the low rate of fluopyram + tebuconazole caused slight stunting in only the first trial of the second phytotoxicity experiment (Table 3 ). Stunting was observed after one application in both experiments. Watermelon seedlings treated with tebuconazole were less than half the size of control seedlings (Table 3). No stunting was observed in the second trial of the second phytotoxicity experiment with any fungicide. The other seven fungicides tested and applications of water never stunted seedlings of any cultivar.

Fungicide efficacy on grafted plants. Based on incidence of gummy stem blight on whole plants, i.e., disease developing on either scion or rootstock, fungicides were equally effective with both bottle gourd and hybrid squash rootstocks with the exception of mancozeb (rootstock-by-fungicide interaction significant, $P=$ 0.03). When applied to watermelon grafted onto the bottle gourd Emphasis, mancozeb was very effective, as disease incidence was not significantly different from the noninoculated control (Table 4). With the hybrid squash rootstock Strong Tosa, mancozeb was intermediately effective and less effective than cyprodinil and fludioxonil. The other four fungicides were ranked in the same order of effectiveness on both rootstocks.

With both rootstocks, incidence of gummy stem blight on plants treated with thiophanate-methyl was significantly higher than on plants treated with any of the other four fungicides $(P \leq 0.01)$ (Table 4). Performance of thiophanate-methyl varied with respect to the inoculated control treatments in the two trials (trial-by-fungicide interaction significant at $P=0.03$ ). In trial 1 , incidence with thiophanate-methyl, $68.5 \%$, was significantly lower $(P \leq 0.0005)$ than incidence on the grafted and self-grafted controls treated with water, whereas in trial 2, incidence was $99.1 \%$ and as high as the controls. Although a low level of disease developed on a few plants treated with difenoconazole or cyprodinil, incidence with these two fungicides did not differ significantly from the noninoculated control with either rootstock (Table 4). Incidence with cyprodinil + fludioxonil was intermediate: less than the inoculated controls and greater than the noninoculated control.

Fungicide efficacy based on disease severity on whole plants was identical to efficacy based on incidence (Table 4). There were no significant interactions with rootstock or trial. Plants treated with thiophanate-methyl had significantly higher severity than the other four fungicides, plants treated with mancozeb or cyprodinil + fludioxonil had intermediate severity, and disease severity on plants treated with cyprodinil or difenoconazole did not differ significantly from the noninoculated control, which was free of disease $(P<0.005)$.
When gummy stem blight was evaluated only on the watermelon scions, there was no effect of rootstock $(P \geq 0.55)$ and no interaction with fungicides $(P \geq 0.42)$. Nongrafted, inoculated watermelon seedlings were included in both trials with rootstock Emphasis and in the second trial with rootstock Strong Tosa. This treatment was included in the analysis of scion ratings, and disease incidence and severity were as high as on the grafted and selfgrafted inoculated controls (Table 4). Disease ratings on scions showed that, in general, fungicides were ranked in the same order as when whole plants were evaluated: thiophanate-methyl was ineffective compared to the inoculated controls, mancozeb and cyprodinil + fludioxonil were intermediate in effectiveness, and cyprodinil and difenoconazole were the most effective fungicides tested and did not differ from the noninoculated control. However, on scions, cyprodinil had lower incidence and severity than mancozeb, while on rootstocks these two fungicides performed similarly (Table 4).

When incidence of gummy stem blight was rated only on rootstock cotyledons, there again was an interaction between fungicide and trial with thiophanate-methyl $(P=0.02)$ and between rootstock and fungicide with mancozeb $(P=0.03)$ (Table 4$)$. When treated with mancozeb, incidence was greater on Strong Tosa than on Emphasis $(P=0.001)$; rootstock cultivars did not differ with the other treatments. In general, incidence of gummy stem blight based on back-transformed mean values was lower with Emphasis than with Strong Tosa, but this difference was not significant due to the interactions. Mean incidence of gummy stem blight on the self-grafted control, i.e., on watermelon used as a rootstock, was $65 \%$ in trials with both rootstock species. On Emphasis, mancozeb, cyprodinil, and difenoconazole significantly reduced disease incidence, whereas on Strong Tosa, all fungicides except thiophanate-methyl were effective, although mancozeb had a higher incidence than difenoconazole (Table 4). No rootstocks treated with difenoconazole had any disease, and only one Emphasis rootstock treated with cyprodinil was diseased.

\section{Discussion}

When evaluated as seedlings under greenhouse conditions, Lagenaria and Cucurbita rootstock cultivars did not differ from each other or from watermelon in susceptibility to gummy stem blight. Gummy stem blight developed on nonwounded seedlings of bottle gourd and hybrid squash. Even though cucurbit seedlings were wounded in most other studies that examined susceptibility to D. bryoniae, wounding is not necessary for infection $(8,11,13,15)$.

Differences in susceptibility were not observed with rootstock seedlings before grafting or after grafting with seedless watermelon. In contrast to these results, four cultivars of $C$. moschata $\times$

Table 4. Efficacy of fungicides at reducing incidence (DI) and severity (DS) of gummy stem blight in the greenhouse on seedless watermelon 'SuperSeedless® 7187HQ' grafted onto Lagenaria siceraria 'Emphasis' or hybrid Cucurbita 'Strong Tosa' rootstocks ${ }^{\mathrm{v}}$

\begin{tabular}{|c|c|c|c|c|c|c|c|c|c|}
\hline \multirow[b]{2}{*}{ Inoculation } & \multirow[b]{2}{*}{ Grafting } & \multirow[b]{2}{*}{ Fungicide treatment } & \multicolumn{2}{|c|}{ DI plant } & \multirow[b]{2}{*}{ DS plant } & \multirow[b]{2}{*}{ DI scion } & \multirow[b]{2}{*}{ DS scion } & \multicolumn{2}{|c|}{ DI rootstock } \\
\hline & & & Emphasis & Strong Tosa & & & & Emphasis & Strong Tosa \\
\hline Inoculated & Grafted & Water & $100.0 \mathrm{a}^{\mathrm{w}}$ & $97.7 \mathrm{a}$ & $15.1 \mathrm{a}$ & $94.7 \mathrm{a}$ & $15.6 \mathrm{a}$ & $13.5 \mathrm{ab}$ & $77.9 \mathrm{a}$ \\
\hline Inoculated & Self-grafted ${ }^{\mathrm{x}}$ & Water & $100.0 \mathrm{a}$ & $93.4 \mathrm{a}$ & $8.2 \mathrm{ab}$ & $94.6 \mathrm{a}$ & $15.8 \mathrm{a}$ & $65.4 \mathrm{a}$ & $65.1 \mathrm{a}$ \\
\hline Inoculated & Grafted & Thiophanate methyl & $85.4 \mathrm{a}$ & $91.2 \mathrm{a}$ & $4.9 \mathrm{~b}$ & $79.9 \mathrm{a}$ & $8.1 \mathrm{a}$ & $5.3 \mathrm{ab}$ & $30.9 \mathrm{ab}$ \\
\hline Inoculated & Grafted & Mancozeb $^{y}$ & $7.7 \mathrm{bc}$ & $47.6 \mathrm{~b}$ & $0.1 \mathrm{c}$ & $21.8 \mathrm{~b}$ & $0.3 \mathrm{~b}$ & $0.00 \mathrm{~d}$ & $6.1 \mathrm{bc}$ \\
\hline Inoculated & Grafted & Cyprodinil + fludioxonil & $36.6 \mathrm{~b}$ & $24.3 \mathrm{bc}$ & $0.6 \mathrm{~cd}$ & $17.8 \mathrm{bc}$ & $0.4 \mathrm{~b}$ & $3.8 \mathrm{abc}$ & $0.1 \mathrm{~cd}$ \\
\hline Inoculated & Grafted & Cyprodinil & $11.4 \mathrm{bc}$ & $6.1 \mathrm{~cd}$ & $0.02 \mathrm{de}$ & $3.5 \mathrm{~cd}$ & $0.01 \mathrm{c}$ & $0.01 \mathrm{~cd}$ & $0.2 \mathrm{~cd}$ \\
\hline Inoculated & Grafted & Difenoconazole & $2.5 \mathrm{c}$ & $2.3 \mathrm{~d}$ & $0.00 \mathrm{e}$ & $1.5 \mathrm{~d}$ & $0.00 \mathrm{c}$ & $0.00 \mathrm{~d}$ & $0.0 \mathrm{~d}$ \\
\hline None & Grafted & Water & $0.0 \mathrm{c}$ & $0.0 \mathrm{~d}$ & $0.00 \mathrm{e}$ & $0.0 \mathrm{~d}$ & $0.00 \mathrm{c}$ & na & na \\
\hline Inoculated & None & Water & $\mathrm{na}^{\mathrm{z}}$ & na & na & $97.3 \mathrm{a}$ & $11.5 \mathrm{a}$ & na & na \\
\hline \multicolumn{3}{|c|}{$P$ value for comparisons } & $\leq 0.01$ & $\leq 0.01$ & $<0.005$ & $\leq 0.01$ & $\leq 0.01$ & $\leq 0.01$ & $\leq 0.01$ \\
\hline
\end{tabular}

v Values are back-transformed means after analysis of variance on transformed data. Disease incidence on whole plants and scions was transformed with arcsine of the square root, and disease incidence on rootstocks and all severity values were transformed by calculating the 0.2-root of the value.

${ }^{\text {w }}$ Means followed by the same letter within columns are not significantly different at the probability given in the last row of the column based on $t$ tests of least-squares means.

${ }^{x}$ Seedless watermelon scion grafted onto seedless watermelon rootstock.

${ }^{y}$ There was a significant $(P=0.03)$ interaction between fungicide and rootstock with DI plant and DI rootstock that was due solely to different incidence values with mancozeb on the two rootstocks.

${ }^{\mathrm{z}} \mathrm{na}=$ Treatment not included in analysis of variance. 
C. maxima used as rootstocks with Cucumis melo were less susceptible to the foliar blight and stem canker phases of gummy stem blight than five $C$. melo scions, two $C$. melo rootstocks, and single cultivars of L. siceraria, Cucurbita maxima, and C. moschata $(10,39)$. It is possible that these differences between Cucurbita and melon were apparent, whereas differences between Cucurbita and watermelon were not, because $C$. melo seedlings are more susceptible to gummy stem blight than watermelon seedlings are (25). Disease severities observed in the current study on inoculated controls were comparable to those observed in a previous study, when severities of gummy stem blight ranged from 1.5 to $17.4 \%$ on watermelon seedlings inoculated with a number of genetically different isolates (25). Transplant growers do not need to use different cultural practices for rootstock and watermelon seedlings to minimize development of gummy stem blight during greenhouse production. Rootstock cultivars of Lagenaria and Cucurbita can be chosen based on graft compatibility, resistance to diseases other than gummy stem blight, and yield and quality improvements (40).

Grafting watermelon on rootstocks of other cucurbits did not reduce incidence or severity of gummy stem blight compared to selfgrafting onto watermelon or not grafting. Apparently, the physiological responses of the rootstock and scion seedlings to wounding and regrowth during grafting did not affect susceptibility to $D$. bryoniae (29).

In general, fungicides performed similarly on grafted plants with Emphasis bottle gourd and Strong Tosa hybrid squash as the rootstock. This was expected, since these two rootstock cultivars and watermelon did not differ in susceptibility to gummy stem blight. Thus, it is not necessary to consider rootstock or scion when selecting fungicides to prevent or manage gummy stem blight. The same fungicides can be used on rootstock seedlings and watermelon seedlings. It was not known why mancozeb was more effective on Emphasis than on Strong Tosa, other than to note that the difference occurred in disease development on the rootstock portion of grafted plants, not on the scion.

It is clear from this study that fungicides that control gummy stem blight in the field cannot simply be used in the greenhouse without considering efficacy and phytotoxicity to rootstock and watermelon seedlings. Difenoconazole and cyprodinil (applied separately) were the most effective fungicides tested in the greenhouse. However, in one of the few field studies to evaluate cyprodinil applied as a single product without a rotation partner, it did not control gummy stem blight on watermelon (34). It is unknown why cyprodinil was effective in the current greenhouse study when applied at $0.37 \mathrm{~kg}$ a.i./ha, but it was completely ineffective in the field at $0.47 \mathrm{~kg}$ a.i./ha. In the current study, there were no differences between cyprodinil and cyprodinil + fludioxonil. The same result has been reported consistently from field trials on watermelon that included both fungicides $(12,38)$. Difenoconazole, however, was more effective than cyprodinil + fludioxonil. Difenoconazole also was more effective than either thiophanate-methyl, which was ineffective, or mancozeb, which was moderately effective. These results match those from recent field evaluations against gummy stem blight on watermelon $(27,33)$. Currently, neither difenoconazole nor cyprodinil is labeled as a stand-alone active ingredient for use on cucurbits.

Several fungicides were phytotoxic on rootstock or watermelon seedlings in the greenhouse. Fluopyram + tebuconazole caused phytotoxicity on rootstock cultivars in each experiment in which it was tested. Cyprodinil + difenoconazole and copper hydroxide also injured rootstock seedlings in half or more of the trials. Because plants are placed into humidity chambers for 1 week after grafting, injured tissue could be colonized by saprophytic fungi that cause additional loss of healthy leaf tissue. Thus, fungicides that are phytotoxic should not be used on seedlings, particularly before grafting. Copper hydroxide, if it is applied in 935 liters/ha instead of 467 liters/ha (the volume tested in this study), is safe to use on Emphasis and Strong Tosa, as reported previously (20).

Tebuconazole consistently stunted Cucurbita, Lagenaria, and watermelon seedlings to a degree where they could not have been used in grafting, as the hypocotyls were too short to hold the clips connecting the scion and rootstock hypocotyls (14). Because tebuconazole stunted seedlings of all three genera, it was likely that the stunting observed with fluopyram + tebuconazole on Cucurbita and watermelon also was due to the tebuconazole component. The same amount of tebuconazole (100 g per 467 liters) was applied with both treatments. In a previous study, Strong Tosa and Emphasis seedlings were stunted after applications of tebuconazole and cyprodinil plus fludioxonil (20). It is not known why stunting was not observed with cyprodinil plus fludioxonil in the current study. Nevertheless, cucurbit transplant producers are unlikely to use any fungicide that has shown phytotoxicity under any conditions.

To maintain the usefulness of fungicides for controlling gummy stem blight in field and greenhouse, transplant producers must practice sound strategies to minimize the risk of insensitivity to additional fungicides developing in D. bryoniae (5). Greenhousegrown transplants infected with strobilurin-insensitive and boscalid-insensitive isolates of $D$. bryoniae have been implicated as a source of fungicide-insensitive isolates found in the field $(17,19,36)$. Mancozeb and cyprodinil + fludioxonil were equally effective in this study. Although these two fungicides were less effective than difenoconazole and cyprodinil, they are the two effective fungicides identified in this study that may legally be applied to cucurbits at this time. Because mancozeb has multiple modes of action, the risk of insensitivity, even with greenhouse use, is low. The mixture of two active ingredients in cyprodinil + fludioxonil also should reduce the risk of fungicide insensitivity (5). In addition, growers can reduce the risk of fungicide insensitivity by using fungicides not registered for greenhouse use, such as chlorothalonil, for the first application to watermelon transplanted in the field.

\section{Acknowledgments}

I thank V. DuBose, G. Baccari, and J. Dufault for technical assistance; the National Watermelon Association for partial funding; Abbott \& Cobb for donating seedless watermelon seed; and Syngenta for donating seed of the rootstocks. This material is based upon work supported by NIFA/USDA under project number SC-1700294. Technical Contribution No. 6094 of the Clemson University Experiment Station.

\section{Literature Cited}

1. Arny, C., and Rowe, R. C. 1991. Effects of temperature and duration of surface wetness on spore production and infection of cucumbers by Didymella bryoniae. Phytopathology 81:206-209.

2. Aveskamp, M. M., de Gruyter, J., Woudenberg, J. H. C., Verkley, G. J. M., and Crous, P. W. 2010. Highlights of the Didymellaceae: A polyphasic approach to characterise Phoma and related pleosporalean genera. Stud. Mycol. 65:1-60.

3. Bala, G., and Hosein, F. 1986. Studies on gummy stem blight disease of cucurbits in Trinidad. Trop. Agric. (Trinidad) 63:195-197.

4. Boughalleb, N., El Mahjoub, M., Abad-Campos, P., Pérez-Sierra, A., García-Jiménez, J., and Armengol, J. 2007. First report of gummy stem blight caused by Didymella bryoniae on grafted watermelon in Tunisia. Plant Dis. 91:468.

5. Brent, K. J., and Holloman, D. W. 2007. Fungicide resistance in crop pathogens: How can it be managed? Fungicide Resistance Action Committee Monogr. 1, 2nd ed. Crop Life International, Brussels.

6. Brown, M. E., Howard, E. M., and Knight, B. C. 1970. Seed-borne Mycosphaerella melonis on cucumber. Plant Pathol. 19:198.

7. Cedeño, L., Carrero, C., and Quintero, K. 2000. Gummy stem blight caused by Didymella bryoniae on watermelon transplants in Mérida, Venezuela Fitopatol. Venezolana 13:26-29.

8. Chiu, W. F., and Walker, J. C. 1949. Physiology and pathogenicity of the cucurbit black-rot fungus. J. Agric. Res. 78:589-615.

9. Cohen, R., Burger, Y., Horev, C., Koren, A., and Edelstein, M. 2007. Introducing grafted cucurbits to modern agriculture: The Israeli experience. Plant Dis. 9:916-923.

10. Crinò, P., Lo Bianco, C., Rouphael, Y., Colla, G., Saccardo, F., and Paratore, A. 2007. Evaluation of rootstock resistance to Fusarium wilt and gummy stem blight and effect on yield and quality of a grafted 'Inodorus' melon. HortScience 42:521-525.

11. dos Santos, G. R., Ferreira, M. A. S. V., Pessoa-Filho, M. A. C. P., Ferreira, M. E., and Café-Filho, A. C. 2009. Host specificity and genetic diversity of Didymella bryoniae from Cucurbitaceae in Brazil. J. Phytopathol. 157:265273.

12. Everts, K. L., and Armentrout, D. K. 2004. Evaluation of fungicides for managing gummy stem blight on watermelon, 2003. Fungic. Nematicide 
Tests 59:V047. Online publication. doi:10.1094/FN59

13. Grossenbacher, J. G. 1909. A Mycosphaerella wilt of melons. New York (Geneva) Agric. Exp. Stn. Tech. Bull. 9:193-229.

14. Hassell, R. L., Memmott, F., and Liere, D. G. 2008. Grafting methods for watermelon production. HortScience 4:1677-1679.

15. Jensen, B. D., Massawe, A., and Swai, I. S. 2011. First report of gummy stem blight caused by Didymella bryoniae on watermelon and confirmation of the disease on pumpkin in Tanzania. Plant Dis. 95:768.

16. Keinath, A. P. 1996. Spread of Didymella bryoniae from contaminated watermelon seed and transplants in greenhouse and field environments. Pages 65-72 in: Recent Research Developments in Plant Pathology, Vol. 1. S. G. Pandalai, ed. Research Signpost, Trivandrum, India.

17. Keinath, A. P. 2009. Sensitivity to azoxystrobin in Didymella bryoniae isolates collected before and after field use of strobilurin fungicides. Pest Manag. Sci. 65:1090-1096.

18. Keinath, A. 2011. From native plants in Central Europe to cultivated crops worldwide: The emergence of Didymella bryoniae as a cucurbit pathogen. HortScience 46:532-535.

19. Keinath, A. P. 2012. Differential sensitivity to boscalid in conidia and ascospores of Didymella bryoniae and frequency of boscalid-insensitive isolates in South Carolina. Plant Dis. 96:228-234.

20. Keinath, A. P., and DuBose, V. B. 2012. Controlling powdery mildew on cucurbit rootstock seedlings in the greenhouse with fungicides and biofungicides. Crop Prot. 42:338-344.

21. Keinath, A. P., Farnham, M. W., and Zitter, T. A. 1995. Morphological, pathological, and genetic differentiation of Didymella bryoniae and Phoma spp. isolated from cucurbits. Phytopathology 85:364-369.

22. Keinath, A. P., and Zitter, T. A. 1998. Resistance to benomyl and thiophanate-methyl in Didymella bryoniae from South Carolina and New York. Plant Dis. 82:479-484.

23. King, S. R., Davis, A. R., Liu, W., and Levi, A. 2008. Grafting for disease resistance. HortScience 43:1673-1676.

24. Koike, S. T. 1997. First report of gummy stem blight, caused by Didymella bryoniae, on watermelon transplants in California. Plant Dis. 81:1331.

25. Kothera, R. T., Keinath, A. P., Dean, R. A., and Farnham, M. W. 2003. AFLP analysis of a worldwide collection of Didymella bryoniae. Mycol. Res. 107:297-304.

26. Kubota, C., McClure, M. A., Kokalis-Burelle, N., Bausher, M. G., and
Rosskopf, E. N. 2008. Vegetable grafting: History, use, and current technology status in North America. HortScience 43:1664-1669.

27. Langston, D. B., Jr., and Sanders, F. H., Jr. 2010. Evaluation of fungicide sprays on gummy stem blight of watermelon in Georgia IV, 2009. Plant Dis. Manag. Rep. 4:V139. Online publication. doi: 10.1094/PDMR04

28. Lee, D.-H., Mathur, S. B., and Neergaard, P. 1984. Detection and location of seed-borne inoculum of Didymella bryoniae and its transmission in seedlings of cucumber and pumpkin. Phytopathol. Z. 109:301-308.

29. Lee, J.-M. 1994. Cultivation of grafted vegetables I. Current status, grafting methods, and benefits. HortScience 29:235-239.

30. Markle, G. M., Baron, J. J., and Schneider, B. A. 1998. Food and Feed Crops of the United States, 2nd ed. Meister Publishing Co., Willoughby, $\mathrm{OH}$

31. Ott, R. L. 1993. An Introduction to Statistical Methods and Data Analysis, 4th ed. Wadsworth Publishing Company, Inc., Belmont, CA.

32. Roy, A. J. 1967. Some fungi from Almora. Indian Phytopathol. 20:340-348.

33. Sanders, F. H., Jr., and Langston, D. B., Jr. 2010. Evaluation of fungicide sprays on gummy stem blight of watermelon in Georgia I, 2009. Plant Dis Manag. Rep. 4:V152. Online publication. doi: 10.1094/PDMR04

34. Seebold, K. W., and Langston, D. B., Jr. 2004. Evaluation of fungicides for control of gummy stem blight of watermelon, 2003. Fungic. Nematicide Tests 59:V140. Online publication. doi:10.1094/FN59

35. Steele, R. G. D., and Torrie, J. H. 1980. Principles and Procedures of Statistics: A Biometrical Approach. 2nd ed. McGraw Hill Book Company, New York.

36. Stevenson, K. L., Langston, D. B., Jr., and Seebold, K. W. 2004. Resistance to azoxystrobin in the gummy stem blight pathogen documented in Georgia. Online. Plant Health Progress doi:10.1094/PHP-2004-1207-01-RS

37. Thaung, M. M. 2008. Pathologic and taxonomic analysis of leaf spot and tar spot diseases in a tropical dry to wet monsoon ecosystem of lowland Burma. Australas. Plant Pathol. 37:180-197.

38. Thornton, A. C., Adams, M. L., and Holmes, G. J. 2005. Evaluation of fungicide for control of gummy stem blight of watermelon, 2004. Fungic. Nematicide Tests 60:V140057. Online publication. doi:10.1094/FN60

39. Trionfetti Nisini, P., Buzi, A., Granati, E., Chilosi, G., Crinò, P., and Magro, P. 2000. Screening for resistance to Didymella bryoniae in rootstocks of melon. OEPP/EPPO Bull. 30:1-3.

40. Yetisir, H., and Sari, N. 2003. Effect of different rootstock on plant growth, yield and quality of watermelon. Aust. J. Exp. Agric. 43:1269-1274. 